\title{
Partidos políticos y acciones trasnacionales: El Comité para América Latina y el Caribe de la Internacional Socialista (1976-1983)
}

\section{Political parties and transnational actions: The Socialist International Committee for Latin America and the Caribbean (1976-1983).}

\author{
Fernando Pedrosa*
}

\section{Resumen}

Este artículo mostrará las formas de acción política trasnacionales que los partidos políticos y sus dirigentes practicaban durante la etapa de democratización de América Latina. Particularmente se abordará la acción del Comité para América Latina y el Caribe de la Internacional Socialista a través del cual se podrá observar e interpretar la actividad trasnacional de estos actores políticos de una manera más detallada y la forma en que actúan en el marco de fuertes restricciones externas e internas.

Palabras clave: Socialdemocracia - Transiciones - Trasnacionalismo Democratización

\begin{abstract}
This article will show the forms of transnational political action that political parties and their leaders practiced during the stage of democratization in Latin America. Particularly, will address the action of the Committee for Latin America and the Caribbean of the Socialist International. Through this network, the activity of these transnational political actors in a more detailed manner can observed. Also the way they operate under strong external and internal constraints.

Keywords: Social democracy - Transitions - Trasnacionalism Democratization
\end{abstract}

\footnotetext{
* Argentino. Historiador. Instituto de Estudios de América Latina y el Caribe, Facultad de Ciencias Sociales, Universidad de Buenos Aires ferpedrosa@gmail.com
} 


\section{Introducción}

El objetivo de este artículo es presentar algunos resultados de una investigación sobre un tema que no ha sido muy trabajado: el papel jugado por la socialdemocracia europea y su principal organización trasnacional, la Internacional Socialista (IS), durante los procesos de transición a la democracia de la 'tercera ola' en América Latina.

A la vez, esta cuestión se inscribe en una temática más amplia, tampoco demasiado abordada, como es la de las estrategias trasnacionales de los partidos políticos latinoamericanos en años de dictaduras, revoluciones y autoritarismos diversos.

Aun con sus dirigentes en el exilio, perseguidos, incluso muertos o con organizaciones en relaciones ambiguas con los gobiernos de turno, fueran o no democráticos, los actores partidarios también cuentan, ya que generan relaciones, acciones y recursos dirigidos a ocupar el poder en algún momento, en un confuso y a veces contradictorio mapa de redes e intereses en tensión.

El artículo mostrará con detalle que, a pesar de cierta subestimación, las política de las organizaciones partidarias y sus líderes lejos estaba de ser estática, ausente, encerrada dentro de fronteras nacionales o ligada a los pocos actores que dominaban la escena internacional en el formato impuesto bajo la guerra fría.

La primera parte de este trabajo pasará rápida revista a algunas de las diversas cuestiones que se debaten en torno a los aspectos internacionales y trasnacionales en los procesos de democratización. La segunda parte expondrá la situación de la IS a partir de 1976, cuando produjo un cambio organizativo que impulsó a la organización socialdemócrata a los primeros planos de la geopolítica de la época.

En la tercera parte se avanzará en describir y analizar la conformación y las actividades realizadas por el Comité para América Latina y el Caribe de la Internacional Socialista (CALCIS), tomándolo como un ejemplo de la política trasnacional que caracterizaba a la política de la época. Finalmente se presentarán algunas conclusiones vinculadas a las cuestiones abiertas en el texto. ${ }^{1}$

\footnotetext{
${ }^{1}$ Para describir detalladamente las actividades que los políticos latinoamericanos y europeos realizaban en el CALCIS, este trabajo se basa, fundamentalmente, en los archivos de la IS y Bernt Carlsson, ubicados en el Internationaal Instituut voor Sociale Geschiedenis (IISG) de la ciudad de Ámsterdam, como también en diversas entrevistas personales.
} 
Fernando Pedrosa, Partidos políticos y acciones trasnacionales: El Comité para América Latina y el Caribe de la Internacional Socialista (1976-1983) / Political parties and transnational actions: The Socialist International Committee for Latin America and the Caribbean (1976-1983), Revista Izquierdas.cl, número 22, enero 2015, ISSN 0718-5049, Santiago de Chile, pp. 48-77

\section{Lo trasnacional en los estudios sobre la democratización en América Latina}

La cuestión sobre el origen (externo o interno) del cambio de régimen ha sido motivo de investigación y de diferentes evaluaciones por parte de expertos en las Ciencias Sociales. ${ }^{2}$

Una de las primeras preguntas que cruzó los debates académicos fue acerca de quién tuvo la preponderancia (el entorno internacional o los actores nacionales) a la hora de explicar la caída del régimen autoritario y la apertura y el rumbo adoptado por la transición hacia un nuevo régimen (Whitehead, 1994).

Luego, también cómo fue la relación entre ambos aspectos y qué características tuvo la presencia de actores y factores externos en sociedades nacionales. ${ }^{3}$ El punto de vista predominante, sobre todo desde la llamada transitología, puso énfasis en la separación de ambas dimensiones. ${ }^{4}$

Enmarcados en esa tradición, trabajos fundantes como los de O`Donnell et al (1988), se centraron en las elites nacionales y subestimaron la influencia política que viniera por fuera de las fronteras nacionales. Sobre todo a la hora de explicar el origen del cambio de régimen, el inicio de la transición y la posterior consolidación democrática. Esta perspectiva fue predominante en los estudios sobre la democratización en América Latina influyendo en las investigaciones posteriores (Schmitter, 2012).

Con el correr del tiempo las posiciones fueron cambiando (Whitehead, 1992) pero los debates se extienden hasta la actualidad (Schmitter, 2012). En este sentido y para superar estos enfoques demasiado rígidos es imprescindible retomar el concepto de política "trasnacional" para cuando, al menos uno de los actores participantes en esta interacción, es de carácter no gubernamental (Keohane y Nye, 1971).

La aplicación sistemática del concepto "trasnacional" -en lugar o junto al de "internacional"- dio lugar a una prolífica literatura que, si bien inicialmente se aplicó a las transiciones europeas, luego se extendió a Latinoamérica. ${ }^{5}$

Frente a las posiciones que abordaban los cambios de régimen como una mera sucesión de eventos nacionales sin relación con el escenario mundial, se reconocía que los procesos de

\footnotetext{
${ }^{2}$ Por ejemplo en la clásica obra de Morlino (1985).

${ }^{3}$ Los "actores internacionales" serían los protagonistas, las personas y organizaciones que en su accionar concretan las estrategias más allá del éxito que alcancen en esta tarea. Los "factores internacionales" serían los elementos contextuales, geopolíticos, regionales que influyen, estimulan o restringen las posibilidades de elección estratégica de los actores (Malefakis, 1982).

${ }^{4}$ Se denominó así a la sub área de la Ciencia Política que abordó sistemáticamente el estudio de los procesos de transiciones a la democracia de la tercera ola.

${ }^{5}$ Además, estos enfoques permiten unir distintos ámbitos de la política (local, nacional, mundial) con visiones más integrales acerca de cómo los distintos actores se relacionan (Keck y Sikking, 2000).
} 
Fernando Pedrosa, Partidos políticos y acciones trasnacionales: El Comité para América Latina y el Caribe de la Internacional Socialista (1976-1983) / Political parties and transnational actions: The Socialist International Committee for Latin America and the Caribbean (1976-1983), Revista Izquierdas.cl, número 22, enero 2015, ISSN 0718-5049, Santiago de Chile, pp. 48-77

transición habían tenido un marcado carácter global y que, en muchos casos, los actores trasnacionales habían sido importantes para su desarrollo. ${ }^{6}$

En este marco, la propuesta teórica de Pridham (1991) puso énfasis en la interacción que se producía entre los distintos aspectos nacionales e internacionales particularmente, en lo referido al cambio de régimen ya que "la consideración crucial es acerca de la interacción entre este entorno externo y el cambio de régimen interno".

Pridham propuso también observar los fenómenos externos entendiéndolos como procesos de interacción que poseían influencias reales sobre los sistemas domésticos, al tiempo que una acción inversa (desde adentro hacia fuera) influenciaba también al sistema internacional. Esta idea permitió superar las visiones más estáticas (y con sesgos nacionalistas) ofrecidas desde la transitología clásica.

Al mismo tiempo, señalaba que los principales problemas para su estudio se encontraban en la combinación de marcos teóricos inadecuados $\mathrm{y}$, sobre todo, en la ausencia de información empírica debido a la conjunción de coyunturas muy complejas (como la guerra fría, revoluciones o dictaduras) que estimularon a los actores a cubrir sus huellas.

Los problemas empíricos derivan de la naturaleza confidencial de actividades políticas que cruzan fronteras "entre países" [...] En este caso, la dificultad es la falta de pruebas concretas sobre algunos aspectos de las recientes transiciones a la democracia por razones de restricciones oficiales a las fuentes y archivo. ${ }^{8}$

En la última década -posiblemente desde un tanto antes- la producción sistemática sobre la democratización volvió a aumentar aunque esta vez, de la mano de la Historia (Mira DelliZotti, 2010). Numerosos trabajos se han dedicado a las cuestiones abiertas con la aparición de las dictaduras, la violencia política y la vuelta de las democracias. ${ }^{9}$

Particularmente desde la llamada Historia reciente se reforzó el interés en el rol jugado por los organismos de DD.HH, el sindicalismo, los grupos armados, las izquierdas radicales, sus intelectuales y los estudios biográficos de quienes fueron víctimas de la represión estatal sobre todo, en el nivel nacional.

Por esto mismo, los problemas institucionales aparejados por el paso de gobiernos autoritarios a democráticos (con excepción de los vinculados a los DD.HH) pasaron a un segundo plano. Y como lógica consecuencia de la desvalorización de la cuestión del

\footnotetext{
${ }^{6}$ Markarian (2004) y Pedrosa (2012a)

7 Pridham, (1991: 1) Mi traducción.

8 Pridham (1991: 2/20). Mi traducción.

9 Tanto desde enfoques más ligados a la tradicional Historia política contemporánea, como particularmente desde otra orientación historiográfica, enmarcada en un novedoso campo disciplinar autodenominado "Historia reciente". Para profundizar en esto ver Mira Delli-Zotti, (2010).
} 
Fernando Pedrosa, Partidos políticos y acciones trasnacionales: El Comité para América Latina y el Caribe de la Internacional Socialista (1976-1983) / Political parties and transnational actions: The Socialist International Committee for Latin America and the Caribbean (1976-1983), Revista Izquierdas.cl, número 22, enero 2015, ISSN 0718-5049, Santiago de Chile, pp. 48-77

régimen político, se dejó de lado a algunos actores como los partidos políticos, sus organizaciones nacionales e internacionales, sus liderazgos etc. ${ }^{10}$

$\mathrm{Al}$ abordar el estudio de partidos y dirigentes que se encuentran bajo regímenes autoritarios, se está hablando de actores en una relación ambigua con el Estado, de incorporación y expulsión, incluso, en combate con él. Ignorar estos actores puede llevar a perder de vista a protagonistas importantes de los procesos de democratización.

La reconstrucción de información para este enfoque empírico y trasnacional es compleja porque muchas de las decisiones y estrategias fueron tomadas en el marco del secretismo que signaba la época. A esto se debe agregar la dificultad material para conseguir información ya que se encuentra fragmentada, en diversos formatos y países.

La utilización del testimonio oral vino a cubrir esa vacante, que por otra parte, no puede oscurecer la existencia de múltiples repositorios y archivos desde donde abordar la historia reciente, además de los relatos testimoniales de las experiencias personales.

Con esta conjunto de materiales hay que realizar una verdadera "arqueología" de las dimensiones trasnacionales de los procesos de democratización en América Latina, entendiendo esto como la necesidad de buscar y utilizar información diversa, fragmentada, dispersa y muchas veces necesaria de interpretación y filtración metodológica. ${ }^{11}$

\section{La Internacional Socialista en América Latina}

Si bien la cantidad y calidad de los estudios sobre las acciones trasnacionales e internacionales en las transiciones latinoamericanas han crecido en los últimos tiempos, ${ }^{12}$ el lugar ocupado en ellos por los socialdemócratas, sus liderazgos y organizaciones, ha quedado mayormente olvidado. ${ }^{13}$

Esto podría explicarse por diversos motivos. En primer lugar porque se ha privilegiado el estudio de las izquierdas armadas en detrimento de otros proyectos de izquierda, posiblemente menos espectaculares en sus formas o radicales en sus programas, pero no por ello menos influyentes. ${ }^{14}$

\footnotetext{
10 Por ejemplo en Lvovich et al (2011).

11 [...] Para hacerlo metodológicamente, tenemos que identificar los principales actores nacionales, internacionales y transnacionales involucrados, así como llevar a cabo una minuciosa deconstrucción (o reconstrucción) de cómo están relacionadas entre sí sus respectivas acciones. Esto puede ser llamado un enfoque de "interacción". La utilización de este método puede determinar si los actores y las acciones internacionales tienen un papel directo o indirecto y si su influencia es ad hoc, episódica o sostenida Legler y Lean (2005:9).

${ }^{12}$ Por ejemplo Markarian (2004) o Keck y Sikking (2001).

${ }^{13}$ Con excepciones como Mujal León (1989), Grabendorff (2002), Ulianova (2009) o Pedrosa (2012).

${ }^{14}$ Por ejemplo en textos como Angell (1991) o en Meschkat (2010).
} 
Fernando Pedrosa, Partidos políticos y acciones trasnacionales: El Comité para América Latina y el Caribe de la Internacional Socialista (1976-1983) / Political parties and transnational actions: The Socialist International Committee for Latin America and the Caribbean (1976-1983), Revista Izquierdas.cl, número 22, enero 2015, ISSN 0718-5049, Santiago de Chile, pp. 48-77

Esta mirada -a veces maniquea- puede oscurecer las diversas y ambiguas estrategias de los grupos de izquierda (revolucionarios o reformistas) que los llevaron a mantener estrategias y vínculos políticos pragmáticos y flexibles, más allá de la ideología o los discursos formales. ${ }^{15}$

Esto se observa muy particularmente dentro de la Internacional Socialista. La IS es una organización que agrupa a los partidos socialdemócratas y afines y que fue fundada en el año 1951 por los partidos socialistas europeos, de los cuales absorbió su tradición programática y organizativa. A pesar de intentos anteriores, fue durante el año 1976 cuando la IS comenzó un proceso de expansión en todo el mundo y que resultó particularmente efectivo en América Latina.

En el congreso de la IS realizado en Ginebra en 1976, el prestigioso dirigente alemán Willy Brandt asumió la presidencia de la organización acompañado por Bernt Carlsson, un dirigente sueco muy cercano a Olof Palme, como Secretario General ${ }^{16}$. Se conformó así una red de dirigentes políticos que, por diferentes motivos, visualizaban a la IS (y a través de ella, al entorno internacional) como un espacio que les permitía maximizar su propio capital político.

Esta red trasnacional se sostuvo más en las relaciones personales entre los distintos líderes partidarios (y sus necesidades), que en sus coincidencias ideológicas. A tal fin, y desde 1976, la IS organizó en forma permanente encuentros y reuniones que tenían como fin mantener esas vinculaciones (que además se reforzaban por correspondencia, viajes de misiones y delegados, telegramas o vía telefónica).

La red incluía numerosas personas y organizaciones que, además, no necesariamente debían ser socialistas o socialdemócratas. Justamente, uno de los atributos de esta red es que se ramificaba hacia los otros actores como EE.UU. y la URSS incluyendo las internacionales Demócrata Cristiana y Liberal.

El contacto entre los integrantes era así, constante. Eran reuniones formales e informales. Cualquier ocasión era buena para reunir a los integrantes de la red. Asunciones presidenciales, reuniones en la ONU o el aniversario del Partido Radical chileno en el exilio. También numerosas instancias internas de la IS. Además del CALCIS, se reunía el

\footnotetext{
${ }^{15}$ Para el caso de los revolucionarios granadinos ver Heine (1990) para los nicaragüenses, Schori (1994).

${ }^{16}$ Junto a ellos, una camada de líderes de gran prestigio. Entre ellos, el mismo Palme, Françoise Mitterrand, Felipe González, Mario Soares, Bruno Kreisky (Austria), Julius Nyerere (Tanzania) e Izak Rabin (Israel). Además, participaban importantes líderes latinoamericanos, como Carlos A. Pérez de Acción Democrática (AD), José Pepe Figueres y Daniel Oduber del Partido Liberación Nacional (PLN), Michael Manley por el People's National Party de Jamaica (PNP) y José F. Peña Gómez, líder del Partido Revolucionario Dominicano (PRD), quienes fueron los referentes más involucrados con la organización. Pero en esta red también se encontraban Leonel Brizola (Partido Democrático Trabalhista, PDT), Raúl Haya de la Torre (Alianza Popular Revolucionaria Americana-APRA), Daniel Ortega (Frente Sandinista de Liberación Nacional, FSLN) y Omar Torrijos, entre muchos otros.
} 
Fernando Pedrosa, Partidos políticos y acciones trasnacionales: El Comité para América Latina y el Caribe de la Internacional Socialista (1976-1983) / Political parties and transnational actions: The Socialist International Committee for Latin America and the Caribbean (1976-1983), Revista Izquierdas.cl, número 22, enero 2015, ISSN 0718-5049, Santiago de Chile, pp. 48-77

Bureau y el Congreso de la IS, la comisión por Chile, por el desarme, la conferencia de líderes partidarios, el comité de apoyo a la revolución nicaragüense entre otras.

La información fue un elemento diferencial en el contexto internacional de la "guerra fría". La IS tuvo una estrategia muy eficaz a la hora de poder obtener esa información y ello la aventajo con respecto a otros actores.

He vuelto hoy a Portugal después de pasar una semana en América Central, donde fui a la ceremonia oficial de Luis Alberto Monge [...] Naturalmente tuve la oportunidad de hablar con mucha gente para tener una idea acerca de América Central $[. .$.$] veo con gran preocupación el crecimiento constante de las tensiones,$ en una zona donde el conflicto de las Malvinas tiene una gran repercusión [...] En Costa Rica me encontré con Edén Pastora, que también habló con Carlsson. Es debido a esta reunión que le escribo esta carta. ${ }^{17}$

Brandt pensaba que cuantos más líderes y partidos se incorporaran a la IS más poderosa sería ésta, ampliando así su campo de acción y su poder de interlocución frente a las potencias dominantes del mundo bipolar. Esto colocaría a la organización (y a él mismo) en un lugar de privilegio en la escena geopolítica (Muñoz Sánchez, 2012).

Para ello necesitaba una organización con flexibilidad ideológica y cierto manejo de recursos. Esto se logró con distintas estrategias (Pedrosa, 2012). Una muy importante fue, como se dijo anteriormente, integrar a líderes y organizaciones no necesariamente socialistas. Desde el Partido Liberal de Colombia hasta los sandinistas nicaragüenses pasando por el partido del general panameño Omar Torrijos, los revolucionarios granadinos, los socialistas chilenos y los apristas peruanos entre muchos otros.

Lo que importaba a la hora de elegir socios para integrar la IS era su potencial político dentro del país y que tuviera interlocución en zonas "calientes" de la guerra fría. Por ello se priorizó el ingreso de partidos de Centroamérica y el Caribe o de países con influencia regional, como era el caso de Venezuela y Costa Rica.

Otra estrategia fue la apertura del organigrama interno de la IS para políticos de América Latina. Luego de los dos primeros congresos ya había cuatro vicepresidentes latinoamericanos: Gonzalo Barrios (Acción Democrática de Venezuela-AD), Michael Manley (People's National Party de Jamaica-PNP), Anselmo Sule (Partido Radical chileno) y Daniel Oduber (Partido Liberación Nacional de Costa Rica-PLN). Éstas fueron las primeras incorporaciones formales de dirigentes latinoamericanos a la estructura de conducción en la historia de las internacionales obreras socialistas.

Pero el contexto internacional también tenía su influencia en las decisiones estratégicas de los actores y en los resultados que estas obtenían. Durante gran parte del mandato del

${ }^{17}$ Carta de Mario Soares a Willy Brandt, Lisboa, 12/05/1982, IISG 
Fernando Pedrosa, Partidos políticos y acciones trasnacionales: El Comité para América Latina y el Caribe de la Internacional Socialista (1976-1983) / Political parties and transnational actions: The Socialist International Committee for Latin America and the Caribbean (1976-1983), Revista Izquierdas.cl, número 22, enero 2015, ISSN 0718-5049, Santiago de Chile, pp. 48-77

presidente norteamericano Jimmy Carter (1977-1981), se había observado -aun con contradicciones y cuestionamientos- una distensión en las relaciones bipolares.

Esto permitió mayor protagonismo de otros actores que buscaban, a través de la acción trasnacional, evitar la polarización típica de la guerra fría, privilegiando sus propios proyectos e intereses, por sobre los de las entonces llamadas superpotencias.

La asunción de Ronald Reagan (1981-1989), y la crisis económica que abrió la década de 1980, no fueron noticias positivas para la organización socialdemócrata. Los desacuerdos del gobierno norteamericano con la IS fueran cada vez más profundos.

Esto se vio públicamente cuando el gobierno de Reagan presentó su programa para América Central encargado ni más ni menos que a Henry Kissinger. Este informe planteaba discusiones con la IS y los partidos socialdemócratas europeos en el gobierno. Para los norteamericanos, la IS estaba siguiendo una política "equivocada" que los llevaba a fortalecer el espacio soviético en la región.

Este desacuerdo tenía diversos orígenes que el informe atribuía a cálculos políticos e, incluso, cierta adhesión a las posiciones soviéticas. ${ }^{18}$ Poco antes de la asunción de Reagan las condiciones geopolíticas comenzaron a cambiar y eso tendría un fuerte impacto tanto en las estrategias de la IS como en las de sus partidos miembro.

La IS pasaba así, de un entorno positivo a uno hostil en sus proyectos de expansión geopolítica.

\section{El Comité para América Latina y el Caribe de la Internacional Socialista}

La creación de un organismo regional de la IS para los partidos y dirigentes latinoamericanos fue una derivación natural de la influencia lograda por estos a partir de 1976. Mientras que los avances en Asia y África fueron lentos y dificultosos (Devin, 1993), la socialdemocracia europea encontró en América Latina un terreno ideal para consolidar su presencia más allá de tierras europeas.

A cambio, los políticos latinoamericanos buscaban de la IS el apoyo y los recursos (no solo materiales) que otorgaba la cercanía con partidos y líderes europeos que, en su mayoría, eran jefes de gobierno. También deseaban mostrar en sus propios países que ellos eran influyentes en una organización que en esos años era muy prestigiosa. Al mismo tiempo, integrar la IS resolvía el problema de pertenecer al colectivo de la izquierda y no ser acusado de comunista, lo que en ese tiempo no era algo menor.

18 "Las diferencias entre los EE.UU. y Europa sobre el problema de Centroamérica tienen diversas causas. En parte surgen de diferentes puntos de vista acerca del problema de las relaciones Este-Oeste y Norte -Sur. Además, algunos europeos ven cierta ventaja política doméstica en su distanciamiento de nosotros en temas concernientes a este hemisferio. En algunos casos existe también una solidaridad política con las fuerzas revolucionarias de la región" Kissinger (1984:176). 
Fernando Pedrosa, Partidos políticos y acciones trasnacionales: El Comité para América Latina y el Caribe de la Internacional Socialista (1976-1983) / Political parties and transnational actions: The Socialist International Committee for Latin America and the Caribbean (1976-1983), Revista Izquierdas.cl, número 22, enero 2015, ISSN 0718-5049, Santiago de Chile, pp. 48-77

Para la IS, y para los europeos especialmente, un espacio latinoamericano dentro de la IS era una forma de mostrar púbicamente el éxito de la política de "cooperación elástica" (Brandt et al 1975) iniciada en 1976. Para avanzar en esto, se iniciaron una serie de contactos con los principales referentes latinoamericanos ligados a la organización socialdemócrata de modo de conocer cuáles eran las demandas e ideas concretas a la hora de pensar un espacio regional dentro de la IS. ${ }^{19}$

Esto no fue un proceso sencillo. Lo único que estaba claro era la necesidad de crear algún ámbito regional para los latinoamericanos, aunque no había acuerdo sobre qué tipo ni su alcance político.

Los proyectos sobre el tema eran diversos e iban desde la formación de un espacio con autonomía y poder propio hasta la conformación de un espacio testimonial solo creado con fines propagandísticos. Incluso Bernt Carlsson quería incorporar a partidos miembro de la IS de EE.UU y Canadá, lo que fue rechazado por todos los interesados.

Por ello mismo, en una organización acostumbrada a tomar decisiones con grandes consensos, los tiempos de la negociación se fueron estirando hasta llegar al año 1979. Y eso molestaba y mucho a los dirigentes latinoamericanos cuyas necesidades parecían más urgentes. Como no se vislumbraba un resultado a corto plazo, la presión definitiva para la conformación del CALCIS vino del entorno.

El 12 de octubre de 1979, a instancias del Partido Revolucionario Institucional (PRI) se creó la Conferencia Permanente de Partidos Políticos de América Latina (COPPPAL), una organización trasnacional de partidos latinoamericanos. Esto no puede dejar de leerse como una estrategia del PRI -que no era miembro de la IS- para no perder iniciativa ante la socialdemocracia europea que avanzaba a paso firme en la región. ${ }^{20}$

Los miembros latinoamericanos de la IS entendieron que integrarse a la COPPPAL les agregaba mayor poder de negociación ante sus pares europeos y participaron de la reunión inaugural que culminó con la llamada "Declaración de Oaxaca". ${ }^{21}$ Esto se combinó con

\footnotetext{
19 “[...] nos permitimos solicitar a usted su valiosa opinión en el sentido de que nos manifieste cuáles son sus criterios personales y los de su partido en materia tan importante como esta, para que proporcione mayores elementos de juicio cuando se discuta este aspecto en las sesiones del Bureau". Carta de Bernt Carlsson a Daniel Oduber, con copia a Oscar Arias. Londres 23/08/1977, IISG. Cartas similares se enviaron a los demás partidos miembros de la IS.

${ }^{20}$ Años después y con mucho más impacto, el PRI desde el gobierno firmaría la declaración franco-mexicana sobre El Salvador. Allí los mexicanos se aliaron a Françoise Mitterrand quien mantenía una compleja relación con el líder alemán Willy Brandt (Covarrubias, 2013; Martínez Peñate, 2013).

${ }^{21}$ Contraponiéndose a la fama eurocéntrica de la IS y a las acusaciones de colonialismo que caían sobre los partidos europeos, la COPPPAL se fundó "como un foro de partidos nacionalistas que otorga prioridad al tema de la soberanía” (Santos Villarreal, 2009).
} 
Fernando Pedrosa, Partidos políticos y acciones trasnacionales: El Comité para América Latina y el Caribe de la Internacional Socialista (1976-1983) / Political parties and transnational actions: The Socialist International Committee for Latin America and the Caribbean (1976-1983), Revista Izquierdas.cl, número 22, enero 2015, ISSN 0718-5049, Santiago de Chile, pp. 48-77

gestos públicos de impaciencia sobre la forma en que la IS venía retardando su decisión sobre el comité latinoamericano ${ }^{22}$.

Pero sobre todo, esta estrategia se vinculaba con el temor que, finalmente, este nuevo organismo que se estaba pergeñando dentro de la IS, no tuviera más que funciones protocolares o de bajo nivel político (Williams, 1984).

En un documento enviado por los dirigentes latinoamericanos a la IS se realizó una reivindicación del papel de los partidos de la región, destacando su contribución al nuevo perfil de la organización socialdemócrata. Por ello, se exigía una "retribución" en una forma tajante y poco diplomática

Los latinoamericanos hemos dado lustre y un mayor dinamismo a la IS y ésta debe darnos la oportunidad de jugar un mayor rol en sus determinaciones; de todas maneras, estamos dispuestos a jugar ese rol, y si la IS no permite que lo hagamos dentro de ella lo haremos fuera de ella. ${ }^{23}$

La conformación de la COPPPAL daba un asidero mayor a la amenaza y, en ese marco, la IS debió tomar una decisión rápida. Reunida en la ciudad portuguesa de Estoril ese mismo mes de octubre, aprobó unánimemente la creación del CALCIS. La intención fue maximizar la política de la IS hacia la región y darle un marco de contención a las relaciones inestables y muchas veces conflictivas que mantenían las organizaciones y sus dirigentes en América Latina.

Al mismo tiempo se designó a los dirigentes que serían su conducción política, como Presidente fue electo el líder dominicano José F. Peña Gómez líder del Partido Revolucionario Dominicano (PRD) y al salvadoreño Héctor Oquelí, del Movimiento Nacional Revolucionario (MNR) como Secretario Ejecutivo.

Se eligieron cuatro vicepresidentes que fueron los mismos vicepresidentes de la IS (Barrios, Manley, Oduber y Sule). Finalmente, como parte del comité, se designó un miembro por cada subregión: Carlos Andrés Pérez por América del Sur, Luis Alberto Monge (PLN) por América Central y O’Brian Trotman (Barbados Labour Party) por Antillas y Caribe. Para cerrar el grupo de integrantes del Comité, también se incorporaron el presidente (Brandt) y el Secretario general (Carlsson) de la IS.

Analizando a los integrantes del comité se observa que, excepto Anselmo Sule, los restantes eran originarios de Centroamérica y el Caribe. Incluso, sus dos principales autoridades cumplían con ese criterio que parecía crucial en las nuevas estrategias de la IS

\footnotetext{
22 “Latin American Political Report”, No 50, pp. 397, 1979, IISG.

${ }^{23}$ Informe sobre la situación de América Latina presentado a la reunión de Bureau de Lisboa (Estoril), Octubre de 1979. Extractado de Williams (1984:15).
} 
Fernando Pedrosa, Partidos políticos y acciones trasnacionales: El Comité para América Latina y el Caribe de la Internacional Socialista (1976-1983) / Political parties and transnational actions: The Socialist International Committee for Latin America and the Caribbean (1976-1983), Revista Izquierdas.cl, número 22, enero 2015, ISSN 0718-5049, Santiago de Chile, pp. 48-77

en la región. El único extrazona pertenecía a Chile, que, sin embargo, era otra de las áreas privilegiadas por la IS en aquella época (Camacho Padilla, 2012).

La elección de Peña Gómez estuvo más clara porque, además, el reciente triunfo en las elecciones presidencial del PRD era una medalla que la IS quería mostrar a propios y extraños (Hartlyn, 1998). El caso de Oquelí es interesante ya que era un dirigente salvadoreño que pasaba a ser un funcionario rentado de la IS en el marco de la Secretaria general. De este modo, la IS incorporaba a un dirigente de América Latina a su estructura organizativa, full time, destinado a convertirse en una especie de operador político para trabajar en nombre de la IS en la región (Martínez Peñate, 2013).

\section{El CALCIS comienza a funcionar}

A partir que la IS definió las características del Comité y su conducción, empezó a preparar la presentación pública. Y esto debía ser a lo grande, ya que la organización trasnacional socialdemócrata aún estaba en una etapa en que debía consolidarse ante la mirada de aliados y adversarios.

Por ello, se decidió hacerlo en República Dominicana. En medio de un Caribe en ebullición, en un país gobernado por un partido miembro y donde la IS había intervenido directamente para que eso sucediera (Pedrosa, 2012). Esto se complementó con la decisión de enviar a la plana mayor de la IS, lo que le daría un efecto político y publicitario muy importante.

Así se convocó a una Conferencia Regional para América y el Caribe que, entre sus distintas funciones, debería presentar al CALCIS. La IS trató por todos los medios de no dejar nada librado al azar apelando una vez más a la Fundación Friedrich Ebert (FFE) para pagar la papelería, las traducciones simultáneas, hoteles y los pasajes aéreos. La gran cantidad de pasajes que la FFE invirtió en este encuentro es un buen indicador de la importancia que otorgaba tanto al comité como a su presentación pública.

Lo primero fue garantizar la asistencia de los propios, cosa que se logró de sobremanera. ${ }^{24}$ Luego la de los de partidos aliados, ${ }^{25}$ los invitados africanos, ${ }^{26}$ personalidades individuales $^{27}$ y diversos medios de comunicación ${ }^{28}$.

\footnotetext{
${ }^{24}$ Se pagaron billetes aéreo al Partido Socialista Popular (Argentina), Barbados Labour Party, PLN, PR (Chile), El Salvador (2 tickets), Izquierda Democrática (Ecuador), New Jewel Movement (Granada), PNP (Jamaica), Febrerismo (Paraguay, 2 Tickets), Movimiento Electoral del Pueblo (MEP-Venezuela), PDT (Brasil) Frente Unido de la Revolución (FUR) y Partido Socialista Democrático (PSD), ambos de Guatemala y el FSLN. Telex de Bernt Carlsson a Willy Brandt, Londres, 19/03/1980, IISG.

${ }^{25}$ Con el acuerdo de la FFE se ofreció un billete aéreo al Partido Intransigente (PI-Argentina), MIR y MNR-I (Bolivia), Partido Liberal (Colombia), ALIPO (Honduras), Santa Lucia Labour Party, UPM (San Vicente), FA y PS (Uruguay). Telex de Bernt Carlsson a Willy Brandt, Londres, 19/03/1980, IISG.

${ }^{26}$ Namibia SWAPO, ANC (Sudafrica), CCM (Tanzania), UNIP (Zambia), ZANU PF (Zimbabwe). Telex de Bernt Carlsson a Willy Brandt, Londres, 19/03/1980, IISG.
} 
Fernando Pedrosa, Partidos políticos y acciones trasnacionales: El Comité para América Latina y el Caribe de la Internacional Socialista (1976-1983) / Political parties and transnational actions: The Socialist International Committee for Latin America and the Caribbean (1976-1983), Revista Izquierdas.cl, número 22, enero 2015, ISSN 0718-5049, Santiago de Chile, pp. 48-77

Hubo invitaciones no pagas también, sobre todo a medios y políticos norteamericanos. ${ }^{29}$ En general no concurrieron, pero la invitación tenía un fuerte contenido publicitario. ${ }^{30}$ Tanta amplitud en la convocatoria generó debates sobre a quien se debía invitar o no ${ }^{31}$.

La reunión se realizó entre los días 26 y 29 de marzo de 1980 y fue un éxito tanto en la convocatoria como en la repercusión política. Contó con la presencia de 116 delegados (58 de partidos miembros) representando a 42 países. Fue una de las más importantes y numerosas reuniones de políticos del período. ${ }^{32}$ Incluso fue la primera vez que se sumó Françoise Mitterrand, quien ya era un dirigente muy reconocido y que menos de un año después llegaría a ser el presidente francés.

La inauguración fue realizada por el presidente dominicano, Antonio Guzmán, en medio de un clima de expectación y con un gran movimiento de medios de comunicación. La reunión generó un paquete de declaraciones (Santo Domingo resolutions) sobre todas las áreas problemáticas de América Latina. Se redactaron resoluciones para cada uno de los países que vivían coyunturas especiales.

En términos generales, esta declaraciones tenían un impacto mediático, pero sobre todo, mostraban en cada coyuntura dónde se paraba la organización y quienes eran o no sus aliados en ese lugar. La declaración final fue particularmente dura con los EE.UU.

${ }^{27}$ Hipólito Solari Irigoyen y Gregorio Selser (Argentina) Antonio García (Colombia), Jaime Roldós y Omar Torrijos (por indicación expresa de Peña Gómez). Telex de Bernt Carlsson a Willy Brandt, Londres, 19/03/1980, IISG.

${ }^{28}$ XEIPN, Canal Once y Diario Excélsior de México y a los editores de Der Spiegel, Vorwaerts, Nueva Sociedad, Política (México). Telex de Bernt Carlsson a Willy Brandt, Londres, 19/03/1980, IISG.

${ }^{29}$ Los invitados fueron Michelle Einthorn, Joseph Eldrige, Dante Faceli, Donald Fraser, Ronald Helman, Winston Lord, Abraham Lowental, Arthur Schlesinger, Ben Stefanski, Gregory Wolf y Andrew Young. Telex de Bernt Carlsson a Willy Brandt, Londres, 19/03/1980, IISG.

${ }^{30} \mathrm{Se}$ invitó también al presidente del movimiento de no alineados, que en ese momento era, nada menos, que Fidel Castro quien envió un telex diciendo que el movimiento no tuvo tiempo para decidir la concurrencia a la conferencia. Lo cual fue, en definitiva, un alivio para todos.

${ }^{31}$ Por ejemplo con el Partido Demócrata (línea Kennedy), algunos ex Montoneros, la Alianza Socialista (Yugoslavia), el Frente Polisario y el People's National Congress (Guayana). Telex de Bernt Carlsson a Willy Brandt, Londres, 19/03/1980, IISG.

${ }^{32}$ Entre ellos numerosas comitivas de AD, PLN y el local PRD. También Luis Villar Borda y Rodrigo Lara (Partido Liberal, Colombia), Emilio Corbiere (PS, Argentina), Iván Estribí, Gerardo González, Aída Torrijos, Ricardo Águila, Ascanio Villalaz (PRD panameño), Juan Ferreira (Convergencia Democrática de Uruguay), Diego May Zubiría y Oscar Alende (PI), Daniel Bilbao, Néstor Martínez Eraso y Víctor García Costa (PS Argentina), Unison Whiteman y James Hagley de Granada, Carlos Núñez (FSLN), Guillermo Ungo y Antonio Martínez (FDR-El Salvador), Carlos Gallardo (PSD-Guatemala), Rubén Berrios (Partido Independentista de Puerto Rico), Robin Sears (New Democratic Party de Canadá), Giuseppe Scanni (PS de Italia), Carlos Caballero Gatti (Febrerismo), Rodrigo Borja (Ecuador), Henry Matipa, (UNIP, Zambia), Louis Athis (MODELH-Haití), Oscar Debunne (PS Bélgica), Paul Miller (PNP-Jamaica), Habib Thiam (Senegal), Hugo Miranda (PR-Chile), Holger Quiring (SPD), Pierre Schori (PS Suecia), Luis Peláez y Carlos Quiroga (Bolivia), Fanny Simon y Frances Grant (EE.UU.), Ivanka Corti del (PSDI Italia), Maarten Van Traa (PvdA) y Henry Forde (Barbados Labour Party), entre muchos otros. 
Fernando Pedrosa, Partidos políticos y acciones trasnacionales: El Comité para América Latina y el Caribe de la Internacional Socialista (1976-1983) / Political parties and transnational actions: The Socialist International Committee for Latin America and the Caribbean (1976-1983), Revista Izquierdas.cl, número 22, enero 2015, ISSN 0718-5049, Santiago de Chile, pp. 48-77

cuestionando sus políticas para El Salvador, Nicaragua y Jamaica. Pero el reclamo por la independencia de Puerto Rico fue el detalle que molestó particularmente al gobierno norteamericano. ${ }^{33}$

La radicalización de la IS no fue planificada y se debió a algunos sucesos que marcaron el ánimo de los dirigentes al momento de producir las resoluciones finales. Dos días antes de comenzar el evento, fue asesinado el Arzobispo Arnulfo Romero. Durante la inauguración de la Conferencia, se hizo un homenaje y un minuto de silencio por el Arzobispo asesinado.

El clima con la junta salvadoreña era de total repudio y esto se extendió a la Democracia Cristiana (DC) que, a través de José Napoleón Duarte daba apoyo a un nuevo intento de formar un gobierno cívico militar. Esto ayudó a galvanizar a las diferentes delegaciones y se plasmó en el tono severo y unitario de las resoluciones.

En la opinión de la dirigencia de la IS, la conferencia cumplió con los objetivos planificados. Hubo una fuerte repercusión en la opinión pública mundial y se reunió un número importante y diverso de políticos de todo el mundo.

Tanto la URSS como EE.UU. mostraron señales de desagrado por la realización y los resultados de la reunión. No era para menos. Mirándolo en perspectiva, una organización trasnacional compuesta por líderes europeos y de países no alineados latinoamericanos, con un programa diferente al de las potencias dominante del eje bipolar desembarcaban en una zona donde EE.UU y la URSS parecían los únicos autorizados a jugar el juego de la guerra fría.

La presencia de la IS en América Latina había llegado a su máxima expresión. Por decisión del comité, la siguiente reunión se realizaría en Caracas, en septiembre de ese mismo año (1980).

Sin embargo, apenas el comité empezó a andar un poco, las diferencias comenzaron a agrietar el trabajoso consenso mostrado en Santo Domingo. A pesar de su entusiasmo Peña Gómez comenzó a sentir los límites de su poder cuando propuso enviar una misión observadora a Bolivia y el pedido fue rechazado sin debate por Willy Brandt. ${ }^{34}$ En la siguiente reunión trataría de recuperar protagonismo, pero el resultado sería aún peor.

\footnotetext{
${ }^{33}$ El primer secretario de la embajada de USA en Londres, Richard Melton, afirmaba en un comunicado que las resoluciones de la IS le traerán aparejada una pérdida de la credibilidad en el primer mundo, "aunque lo gane en el tercero". Notas de Bernt Carlsson, 15/04/1980, IISG.

34 Telegrama de Bernt Carlsson a José F. Peña Gómez, 10/07/1980, IISG.
} 
Fernando Pedrosa, Partidos políticos y acciones trasnacionales: El Comité para América Latina y el Caribe de la Internacional Socialista (1976-1983) / Political parties and transnational actions: The Socialist International Committee for Latin America and the Caribbean (1976-1983), Revista Izquierdas.cl, número 22, enero 2015, ISSN 0718-5049, Santiago de Chile, pp. 48-77

\section{Segunda reunión del CALCIS}

El CALCIS se reunió los días 12 y 13 de septiembre en Caracas, Venezuela, donde la IS poseía un importante bastión político, recursos y liderazgos, particularmente, aunque no el único, con Carlos Andrés Pérez (Gamus, 1988/1989).

En esa ocasión ya no se buscó generar impacto público, sino cumplir las funciones que fueron previstas en su creación al mismo tiempo que comenzar a posicionarlo como un nuevo operador político en la región, sobre todo, en relación con los conflictos de Centroamérica. ${ }^{35}$

Sin embargo, el bajo perfil no pudo mantenerse porque los problemas organizativos tiñeron toda la reunión. A diferencia de la conferencia anterior, hubo un verdadero caos a la hora de seleccionar a quién se invitaba y a quien no. Participaron, sin saber bien como fueron invitados, la Democracia Cristiana (DC) de Venezuela (con quien la IS estaba muy enfrentada en la región), exiliados cubanos y el Partido Intransigente de Argentina que había sido rechazado anteriormente como miembro. ${ }^{36}$

Carlsson escribió a Brandt diciendo que esta variedad de participantes le daba al comité un carácter amorfo que debía ser revisado. Al mismo tiempo acusaba a Peña Gómez de hacer su propio juego y por ello realizar una serie de invitaciones sin ser discutidas. Quizás la más problemática fue al Partido Socialdemócrata de Nicaragua, ya que eso generó un conflicto con el FSLN.

La explicación del dominicano por estos hechos, resultaba poco creíble. ${ }^{37}$ Sin embargo la IS utilizó (más metafóricamente), los mismos argumentos para defenderse. ${ }^{38}$ Para esa época, lo principal era mantener las buenas relaciones con el FSLN.

Pero sin duda el dislate más problemático ocurrió en un lugar donde la IS no podía cometer errores: la conferencia de prensa. Muchos medios de diversos países estaban allí para escuchar las definiciones del CALCIS que había levantado una expectativa importante. Peña Gómez, Oduber, Pérez y Carlsson eran allí las caras más conocidas.

\footnotetext{
${ }^{35}$ Por ejemplo, encabezados por Daniel Oduber mantuvieron una reunión secreta con el Embajador Goodman y un delegado del Departamento de Estado en Venezuela y que había sido recientemente enviado a Bolivia. Carta (private) de Bernt Carlsson a Willy Brandt, Londres, 26/10/1980, IISG.

${ }^{36}$ Carta (private) de Bernt Carlsson a Willy Brandt, Londres, 26/10/1980, IISG.

37 "Peña Gómez en un momento afirmó que la letra y su firma fueron falsificadas por la CIA". Carta (private) de Bernt Carlsson a Willy Brandt, Londres, 26/10/1980, IISG. Traducción FP.

38 "Dentro del marco amistoso que existe entre el FSLN y la IS, deseo expresar en términos categóricos que la IS no ha invitado al llamado Partido Social Democrático de Nicaragua [...] me permito recordarles que la IS ha rechazado la solicitud de membresía hecha por el Movimiento Democrático Nicaragüense. Las únicas explicaciones que pueden ser dadas para esta invitación - a menos que sea un mero rumor- son: ya sea que ella represente una falsificación efectuada por alguna fuerza siniestra encaminada a dañar las relaciones entre la IS y el FSLN". Carta de Bernt Carlsson a El Directorado (sic) FSLN, Londres, 20/08/1980, IISG.
} 
Fernando Pedrosa, Partidos políticos y acciones trasnacionales: El Comité para América Latina y el Caribe de la Internacional Socialista (1976-1983) / Political parties and transnational actions: The Socialist International Committee for Latin America and the Caribbean (1976-1983), Revista Izquierdas.cl, número 22, enero 2015, ISSN 0718-5049, Santiago de Chile, pp. 48-77

En un largo discurso, el dominicano no tuvo ningún empacho en relatar con todos los detalles una reunión secreta que miembros de la IS habían mantenido con Fidel Castro en Nicaragua, unos meses antes de la segunda reunión del CALCIS. Una vez revelados los pormenores del encuentro, Peña Gómez no se detuvo y continuó relatando la reunión que poco antes habían mantenido con enviados del Departamento de Estado.

Mientras Peña Gómez seguía hablando, los restantes dirigentes socialdemócratas no salían de su asombro. Carlsson relataba a Brandt el incidente manifestando el temor que trajera consecuencias negativas a la IS, ya que ambas reuniones se habían concretado a partir de un compromiso de mantener la confidencialidad, tanto de los encuentros, como de lo allí conversado.

Al finalizar la conferencia de prensa, Pérez pidió reunirse en privado con Carlsson y le solicitó que en la próxima reunión del CALCIS se discutiera sobre la forma en que el comité debería trabajar en el futuro. ${ }^{39}$ Recién realizada la segunda reunión, el panorama del Comité ya parecía incierto. Según el Secretario General de la IS, sino se tomaran las medidas correspondientes, la credibilidad de la organización estaría en juego

\section{La crisis interna frente al conflicto centroamericano}

El año 1981 comenzó con fuertes ruidos entre los partidos latinoamericanos, sobre todo, con el PLN y AD. La IS mantenía una fortísima oposición al gobierno salvadoreño y un importante apoyo al gobierno sandinista. Esto no era del todo compartido por algunos partidos de América Latina. Esto se observaba sobre todo con AD y el PLN que enfrentaban coyunturas electorales y eran acusados rivales ligados a la DC de mantener una actitud cómplice con el avance comunista en la región, sobre todo, por su apoyo a las posiciones de la IS.

La IS recibía presiones cruzadas sobre la cuestión de los gobiernos revolucionarios. ${ }^{40}$ En una carta dirigida a Brandt, el francés Leonel Jospin, parecía acertar en su diagnóstico cuando afirmaba que los partidos europeos no podían ser más radicales que los latinoamericanos en asuntos de la región. ${ }^{41}$

Loa problemas estallaron cuando la IS emitió un duro comunicado donde hablaba de "derribar" al gobierno de Duarte. Además manifestaba el apoyo socialdemócrata "al

\footnotetext{
${ }^{39}$ Carta (private) de Bernt Carlsson a Willy Brandt, Londres, 26/10/1980, IISG.

$40 \mathrm{La}$ Central Latinoamericana de Trabajadores pide información si el MNJ es miembro pleno u observador sobre su situación política. (Telex de Ernst Roemers a Bernt Carlsson, 22/11/1982, IISG). Diversos miembros mandan informaciones que reciben de periódicos sobre la deriva marxista de la revolución de Granada (por ejemplo H. E. Dingels y varias veces Thomas Nowotny, cónsul general de Austria en Nueva York). Se incluye un minucioso reporte sobre la visita de Bishop a la URSS enviado por Klaus Lindenberg a Bernt Carlsson el 27 de septiembre de 1982.

41 Carta de Lionel Jospin a Willy Brandt, París, 15 de Marzo de 1982, IISG.
} 
Fernando Pedrosa, Partidos políticos y acciones trasnacionales: El Comité para América Latina y el Caribe de la Internacional Socialista (1976-1983) / Political parties and transnational actions: The Socialist International Committee for Latin America and the Caribbean (1976-1983), Revista Izquierdas.cl, número 22, enero 2015, ISSN 0718-5049, Santiago de Chile, pp. 48-77

cambio revolucionario en El Salvador [ya que] todos los intentos de lograr un cambio pacífico han sido bloqueados por la violencia y el fraude". ${ }^{42}$

El comunicado de la IS tuvo una amplia repercusión y, por ello, la reacción del PLN fue también pública y terminante con una fuerte difusión en la región. ${ }^{43}$ Antes de hacerlo, sin embargo, la IS fue advertida.

Telegrama firmado por presidente Willy Brandt y Ud. apoyando a movimiento revolucionario El Salvador fue interpretado como apoyo al FMLN cuyo jefe Cayetano Carpio comunista reconocido ha anunciado públicamente la liberación de América Central incluyendo Costa Rica. Sobre dicho telegrama PLN no puede callar y debe disociarse públicamente de la posición de la IS. Respecto a todo lo demás, mantenemos solidaridad y afecto. ${ }^{44}$

Un día después, la dirección del PLN volvió a enviar un mensaje a Carlsson en tono de disculpa y argumentando que debían despegarse de las acusaciones que se le realizaban en la prensa de su país sobre el apoyo al FMLN. ${ }^{45}$

La situación de crisis que se abría entre los latinoamericanos y entre algunos de estos y la conducción de la IS, debía ser contenida rápidamente y en forma pública. Para esto la IS volvió apeló a institucionalizar el conflicto y cerrarlo en un espacio colectivo dentro del organigrama. Así, volvió a ser convocado el CALCIS y decidiendo a la vez que la reunión se concretaría en Panamá.

El CALCIS fue citado de urgencia con dos objetivos. Primero, cerrar la crisis abierta por la declaración del PLN acerca de El Salvador. En segundo lugar, y más importante, discutir las posibilidades de iniciar un proceso de negociación entre las partes para abrir una solución política al conflicto salvadoreño.

La elección de Panamá como sede del encuentro fue muy significativa. El oficialista Partido Revolucionario Democrático (PRD) no era miembro de la IS, pero su poder de convocatoria mostraba la influencia de Torrijos en la zona y sobre la IS en particular. ${ }^{46}$ Por ello, la reunión del CALCIS no era la única que se realizó en el país por aquellos días.

\footnotetext{
${ }^{42}$ Declaración de la IS sobre El Salvador, 23/01/1981, Londres. IISG.

43 "Por la intervención de las fuerzas comunistas en estas luchas, el PLN no comparte los acuerdos recientes que ha adoptado y las apreciaciones que ha mantenido la IS en relación con los procesos políticos de Centroamérica". Pronunciamiento del PLN (comunicado y solicitada). Firman Monge (candidato presidencial PLN), Figueres (Presidente PLN) y Oduber (Presidente Directorio Político). 3/02/1981, IISG.

${ }^{44}$ Telegrama de Oscar Arias a Bernt Carlsson 18/02/1981, IISG.

45 "Este pronunciamiento fue tomado por nuestro directorio político recientemente en vista de la crítica que se le hace al PLN por el supuesto respaldo que le estamos dando a la guerrilla en El Salvador" Telegrama de Oscar Arias a Bernt Carlsson, El día 4/02/1981, IISG.

${ }^{46}$ Ver Blázquez Vilaplana (2006).
} 
Fernando Pedrosa, Partidos políticos y acciones trasnacionales: El Comité para América Latina y el Caribe de la Internacional Socialista (1976-1983) / Political parties and transnational actions: The Socialist International Committee for Latin America and the Caribbean (1976-1983), Revista Izquierdas.cl, número 22, enero 2015, ISSN 0718-5049, Santiago de Chile, pp. 48-77

Aprovechando que Torrijos era interlocutor de casi todos los actores, se concretó una verdadera cumbre de la que no hay demasiados registros. ${ }^{47}$

Además de los líderes de la IS (europeos y latinoamericanos) ${ }^{48}$ hubo enviados del PC cubano, del FSLN, del FMLN (Joaquín Villalobos y Ferman Cienfuegos), el canciller del Gobierno de José Napoleón Duarte y el enviado especial de Reagan y ex jefe de la CIA, Vernon Walters. Resulta difícil pensar que todos coincidieran allí por cuestiones de agenda de las aerolíneas.

Fue él líder panameño quien estimuló a la IS para tomar la iniciativa sobre El Salvador. Torrijos afirmaba que Reagan -quien recién estaba asumiendo la presidencia- estaba en una difícil situación por sus declaraciones durante la campaña pero que la IS debía "ayudarlo" en ese sentido. ${ }^{49}$ Esto se unía a las señales que el FMLN le daba a la IS -a través de Oquelí y Guillermo Ungo- sobre la supuesta voluntad de comenzar una salida política al conflicto (Martínez Peñate, 1997).

El 1 de marzo, se reunieron a instancias del embajador de EE.UU., Ambler Moss (y en su residencia), Vernon Walters con Carlos A. Pérez, Carlsson y Peña Gómez. El día siguiente Carlsson y Oquelí se reunieron con los representantes del PC cubano. En todas las conversaciones sobrevolaba la posibilidad de una mediación de la IS en el conflicto salvadoreño.

Según Carlsson, Walters dijo que EE.UU. admitiría una salida negociada pero insistía en que debía establecerse un gobierno pluralista. Carlsson señala en sus notas que Walters no era una persona confiable para los socialistas, recordando su actuación en contra del gobierno de Allende y en Angola. ${ }^{50}$

Más allá de las pretensiones de la IS de encarar por sí misma un proceso de negociación, primero había que resolver las disidencias internas y luego continuar con lo demás. Y eso se hizo rápidamente porque sabían que varios embajadores de EE.UU. habían informado que otros partidos seguirían al PLN en su condena al FMLN. Por otra parte, por diversos medios se difundió que EE.UU., junto a la DC, estaba detrás de una estrategia para desestabilizar a los partidos socialistas del continente. ${ }^{51}$

Esta vez no hubo invitados especiales y concurrieron a la reunión los principales dirigentes latinoamericanos de la IS, donde los costarricenses estaban en minoría. El CALCIS

\footnotetext{
${ }^{47}$ Con la excepción de Martínez Peñate (1997).

${ }^{48}$ Gracias a las notas encontradas en el archivo de Bernt Carlsson se puede reconstruir la cumbre y la importancia de las personas allí reunidas entre el 28 de febrero y el $1^{\circ}$ de marzo de 1981 . Entre ellos CAP, Peña Gómez, Oquelí, Carlsson, Rui Mateus, Antoine Blanca, Elena Flores y Klaus Lindenberg. Meeting of the SI Committee on Latin American and the Caribbean.. 24/04/1981, IISG.

${ }^{49}$ Meeting of the SI Committee on Latin American and the Caribbean. Draft 2. 24/04/1981, IISG.

${ }^{50}$ Meeting of the SI Committee on Latin American and the Caribbean. Draft 2. 24/04/1981, IISG.

${ }^{51}$ Extraido de Diario El País (España) 3 de marzo de 1981.
} 
Fernando Pedrosa, Partidos políticos y acciones trasnacionales: El Comité para América Latina y el Caribe de la Internacional Socialista (1976-1983) / Political parties and transnational actions: The Socialist International Committee for Latin America and the Caribbean (1976-1983), Revista Izquierdas.cl, número 22, enero 2015, ISSN 0718-5049, Santiago de Chile, pp. 48-77

comenzó la reunión a la ofensiva definiendo la posición del PLN como una desviacionista de derecha. Al mismo tiempo acusaba a EE.UU. por utilizar en forma propagandística esa declaración con el fin de mostrar la división de la IS. ${ }^{52}$

Finalmente, se logró emitir un comunicado unánime, lo que implicó una suerte de retroceso en la declaración del PLN. Allí se negaba que el conflicto salvadoreño fuera una confrontación Este/Oeste, se hacía un llamamiento a resolver el conflicto de manera política y mantenía la solidaridad con el MNR, partido miembro de la IS. ${ }^{53}$

Sin embargo la jugada más arriesgada fue proponer a las partes la mediación de la IS y que Brandt realizara una gestión ante el gobierno de los EE.UU. para contribuir a la solución pacífica. La implicación de Brandt como mediador tuvo más impacto mediático que concreción en la realidad, pero a la IS le sirvió para alejar el fantasma de la división y recuperar protagonismo, incluyendo en la prensa norteamericana. ${ }^{54}$

Carlsson y Pérez siguieron viaje a Washington donde fueron a tantear las posibilidades de la mediación. La reunión fue en el Departamento de Estado con un funcionario de apellido Pendleton que Carlsson conocía de Suecia y con John Bushnell, asistente del Secretario de Estado.

El trato recibido por Carlsson no dejó lugar al optimismo y puso a la mediación en un punto muerto. Para empezar Bushnell cuestionó la imparcialidad de la IS para realizar la mediación propuesta. Sin perder la calma Carlsson respondió que habían contactado con la izquierda de El Salvador, que habrían aceptado una salida política y que estaban preparados para iniciar el proceso sin precondiciones. ${ }^{55}$

Bushnell consideró que la izquierda salvadoreña estaba tomada por su ala marxista leninista y que Guillermo Ungo era sólo una figurehead sin ningún tipo de influencia política. Pero más despectivamente señaló que la izquierda no lograría ganar con política lo que perdió en el campo de batalla, ni aun con la IS de su lado.

Frente a la tímida argumentación de Carlsson acerca de que la radicalización del conflicto llevaría a gente democrática como Ungo a perder poder frente a los extremos, el norteamericano finalizaba la charla lapidariamente:

\footnotetext{
${ }^{52}$ Meeting of the SI Committee on Latin American and the Caribbean. Draft 1. 24/04/1981, IISG.

${ }^{53}$ Meeting of the SI Committee on Latin American and the Caribbean. Draft 1. 24/04/1981, IISG.

${ }^{54}$ Por ejemplo un artículo del New York Times del 3 de marzo de 1981. También otro en The Washington Star de la misma fecha. IISG. También en el Diario El País de España.

55 Some notes on the initiative of the SI Committee for Latin American and the Caribbean regarding El Salvador, 10/03/1981, IISG.
} 
Fernando Pedrosa, Partidos políticos y acciones trasnacionales: El Comité para América Latina y el Caribe de la Internacional Socialista (1976-1983) / Political parties and transnational actions: The Socialist International Committee for Latin America and the Caribbean (1976-1983), Revista Izquierdas.cl, número 22, enero 2015, ISSN 0718-5049, Santiago de Chile, pp. 48-77

No estamos en contra de eso. Tampoco estamos a favor. Nosotros no somos parte del conflicto. Si la IS desea mediar entre las partes en El Salvador, nosotros le deseamos la mayor de las suertes. ${ }^{56}$

La mediación no contó con el visto bueno norteamericano y la IS no deseaba desgastar a Brandt en un asunto perdido de antemano. Antes de volver, Carlsson fue invitado por algunos congresistas a discutir el punto de vista de la IS hacia Centroamérica y algunos aspectos particulares, como la muerte del Arzobispo Romero y la plana mayor del FRD. ${ }^{57}$

Igualmente, se encargó al dirigente alemán Hans-Jürgen Wischnewski la misma misión, pero con un perfil muy bajo al no tratarse de una figura del peso de Brandt. Finalmente con la anécdota de los "guerrilleros de las mil fotocopias" y el desplante que sufrió el mediador, el año 1981 dio un fuerte golpe a las pretensiones de la IS y su presidente para aumentar su presencia global. $^{58}$

Así quedaba clara la falta de voluntad del FMLN de iniciar un proceso de paz y se confirmaba la radicalización del gobierno norteamericano: Paralelamente los sandinistas mostraban una creciente ambigüedad sobre el rumbo de su proyecto democrático. Además, a mitad de año moría Torrijos, un aliado clave en el proyecto socialdemócrata de la región. 59

La segunda guerra fría (Halliday, 1986) mostraba crudamente los límites de la acción trasnacional y las diferencias con los años de la distensión.

\footnotetext{
${ }^{56}$ Some notes on the initiative of the SI Committee for Latin American and the Caribbean regarding El Salvador, 10/03/1981, IISG. Mi traduccion.

${ }^{57}$ Entre ellos el presidente del SubComité para América Latina, Barnes (Demócrata de Virginia) y Aspin (Demócrata de Wisconsin). Some notes on the initiative of the SI Committee for Latin American and the Caribbean regarding El Salvador, 10/03/1981, IISG.

58 "Wischnesky se sienta a negociar con los militares salvadoreños por una parte y por otra parte con los guerrilleros. Cuando la plana mayor de los militares le pone delante una serie de papeles que eran la estrategia de los guerrilleros diciendo "hagamos como que estamos en un proceso de negociación y de paz pero tomemos posiciones y tal" [...] le han engañado claramente. Así que los hemos llamado los guerrilleros de las mil fotocopias. Pues les hicieron fotocopias de todo [...] Wischnesky se levantó de la mesa encabronado e inmediatamente después de salir de regreso a Alemania, se va detrás en un avión una de las guerrilleras, Ana Guadalupe Martínez y alguien más que no recuerdo, para explicarle lo inexplicable”. Entrevista personal a Elena Flores, Madrid, marzo 2006.

${ }^{59}$ Sus sucesores no tuvieron ninguna oportunidad de heredar su liderazgo en la zona "una vez que muere Torrijos lo que está claro es que no dejan jugar más a Panamá. Los americanos hablan con Ricardo de la Esprilla que lo sucede y le dicen "Ud. ya no tiene más nada que hacer en todo el conflicto centroamericano". Entrevista personal a Elena Flores, Madrid, marzo 2006.
} 


\section{El CALCIS en Granada}

El panorama no parecía del todo saludable y la desconfianza interna comenzó a instalarse, particularmente, con los sectores revolucionarios. La siguiente reunión del CALCIS fue convocada rápidamente para tratar de mantener homogéneo el frente latinoamericano. Sin embargo los resultados serían totalmente opuestos a los esperados.

El primer problema a resolver fue dónde realizar la reunión. La idea era mantener la presencia en el Caribe y el Partido Laborista de Barbados hizo la primera oferta al respecto. Sin embargo pronto perdieron el interés en hacerlo allí, posiblemente por los gastos que ocasionaría. La siguiente posibilidad fue Aruba y dicha oferta fue aceptada por el CALCIS. Sin embargo, Peña Gómez en una decisión totalmente inconsulta, decidió cancelar la reunión en el país caribeño.

A cambio, el dominicano propuso realizar el encuentro en isla de Granada, donde una revolución había llegado al poder en 1979 y el partido (New Jewel Movement-NJM) era miembro de la IS (Heine, 1990). La propuesta no dejaba de ser espinosa, ya que en el marco de desconfianza generalizada hacia ese tipo de movimientos, reunirse allí ponía a la IS nuevamente ante una situación de conflicto entre sus miembros.

Anticipándose a esa posibilidad, Carlsson realizó una consulta entre los integrantes del CALCIS que resultó dividida, pero positiva hacia la propuesta de Peña Gómez. El PLN nuevamente se opuso a legitimar con su asistencia un grupo sospechado por su ascendencia marxista leninista, debido al costo político que le supondría en el país.

El venezolano sugirió que Peña Gómez viajara a Granada para hablar con su Primer Ministro, Maurice Bishop. Peña Gómez, argumentando que no tenía tiempo para eso, devolvía la invitación afirmando que debía ser Pérez quien viaje a reunirse con Bishop y garantizar que Granada iría a un sistema pluralista y de libre expresión. La tarea finalmente la cumplió Carlsson, como se verá en páginas siguientes.

En ocasión de una cumbre de líderes partidarios de la IS en Ámsterdam, Carlsson mantuvo varios encuentros con la plana mayor del NJM acordando un punteo de temas para la agenda de la reunión del CALCIS. ${ }^{60}$ Bishop, deseaba discutir acerca de nuevas formas de democracia, lo que era un eufemismo para argumentar por qué las elecciones no formaban parte del proyecto del MNJ.

Carlsson propuso discutir en forma amplia sobre la situación en Granada y el desarrollo de la situación en América Latina. Esto, implicaba evaluar más de cerca la política de Granada e incluirla dentro de los conflictos políticos de la región.

\footnotetext{
${ }^{60}$ Los participantes fueron Carlsson y Oquelí por la IS y Maurice Bishop, Curt Strachman, Unison Whiteman y Abraham Bautista por el MNJ. Extractado de Notes from meeting with the Grenada delegation in Amsterdam at the Sonesta Hotel, 5/05/1981, IISG.
} 
Fernando Pedrosa, Partidos políticos y acciones trasnacionales: El Comité para América Latina y el Caribe de la Internacional Socialista (1976-1983) / Political parties and transnational actions: The Socialist International Committee for Latin America and the Caribbean (1976-1983), Revista Izquierdas.cl, número 22, enero 2015, ISSN 0718-5049, Santiago de Chile, pp. 48-77

En una posición intermedia, Oquelí sugirió que el temario estuviera dedicado a discutir formas de solidaridad con Granada y aspectos organizativos del CALCIS. El acuerdo final fue logrado por consenso pero la posición inicial de Bishop fue bastante recortada. Al acordar la agenda política, el encuentro se dedicó a resolver los temas organizativos.

Carlsson dejó claro que debían prescindir de cualquier tipo de ayuda cubana. ${ }^{61}$ Cuando Bishop planteó pedirle a la COPPPAL asistencia para financiar la traducción simultánea, Carlsson ofreció hacerse cargo de esos costos, que ascendían a 10.000 dólares, a cambio que los esos equipos fueran de la IS. Al ser inmediatamente aceptado, las restantes cuestiones organizativas fueron rápidamente acordadas.

No obstante las relaciones entre los miembros de la IS continuaban siendo ásperas y eso conspiraba contra la posibilidad de reunirlos en los espacios colectivos del organigrama. Cuanto más cerca estuvieran las elecciones en Venezuela, Costa Rica y República Dominicana, más compleja sería la posición de los partidos miembros en esos países, debido a las posiciones radicales que adoptaba la IS en la región.

Así fue que días antes de la reunión, el PLN anunció que no concurriría Granada. En esta ocasión los argumentos fueron directos: mientras el NJM adhiriera a la línea política cubana, no había nada que hablar con ellos. ${ }^{62}$

La cuarta reunión del CALCIS no tuvo el peso político de las realizadas anteriormente en Republicada Dominicana, Venezuela y Panamá. Sin embargo, no fue una reunión menor. Participó una amplia delegación latinoamericana ${ }^{63} \mathrm{y}$, también, delegados observadores de otros partidos miembros de la IS. ${ }^{64}$

Sin embargo, la reunión se transformó en una muestra de apoyo internacional al gobierno del NJM. El comunicado final resultó muy crítico con la posición de EE.UU. en Granada, Nicaragua y El Salvador. En una retórica fuertemente antiimperialista convocaba a un comité de solidaridad y una campaña para alertar sobre los peligros que estos gobiernos podían sufrir por la "agresión imperialista". 65

\footnotetext{
${ }^{61}$ Notes from meeting with the Grenada delegation in Amsterdam at the Sonesta Hotel, 5/05/1981, IISG.

62 "Lamento manifestarle que mientras el gobierno de Granada continúe gravitando hacia la línea política inspirada por la Habana, ni yo ningún representante del partido estará a disposición para asistir a ninguna reunión que se celebre en la isla". Carta de Luis. A . Monge a Bernt Carlsson, San José 10/06/1981, IISG.

${ }^{63}$ En otros se encontraban Carlsson, Bishop, Fénix Agustine, Unison Whiteman y Dessima Williams (MNJ), Julio López, Sylvia Mc Ewan y Gilda Bolt (FSLN), Fernando Martín (PIP de Puerto Rico), Mario Solórzano (PSD de Guatemala), Paul Miller (PNP), Adelso González Urdaneta (MEP venezolano), Gerardo Godoy (MNR de El Salvador) y delegaciones de Curaçao, Antigua, Santa Lucía.

${ }^{64}$ Compuesta por José Luis Ibáñez (PSOE), Antoine Blanca (PS francés), Nancy Lieber (DSOC de USA) Conny Frediksson (PS sueco), Social Democrats de USA (Rita Freedman y Bruce McColm) y Bob Ogle (Canadá Nacional Democratic Party). También se recibieron adhesiones de Willy Brandt y de los partidos de Finlandia, Gran Bretaña y Suiza.

${ }^{65}$ Declaration of the CALCIS, Granada, Julio, 1981, IISG
} 
Sólo los partidos latinoamericanos presentes firmaron dicho documento, porque la declaración fue una de las más duras que el CALCIS hubiera firmado en su corta vida.

Durante los dos días de debate, muchos de los miembros de la IS aprovecharon para visitar la isla y hacerse una opinión propia de la situación política y social. Los delegados norteamericanos se fueron con una pésima impresión y no tardaron en hacerla pública en la prensa de ese país, que además, dio mucha atención a la realización del evento en Granada. ${ }^{66}$ En palabras de Carlsson, la situación que observó parecía producto de un viaje en la máquina del tiempo. ${ }^{67}$

Conscientes del problema interno que se estaba produciendo dentro de la organización, la conducción de la IS decidió tratar nuevamente de procesarlo internamente y al mayor nivel posible. Pero el CALCIS no parecía ser el lugar ya que era el único espacio del organigrama donde los europeos no tenían ninguna injerencia ni poder para imponerse o al menos mediar con posibilidades razonables de éxito.

Así, es que se convocó a una Conferencia de Líderes partidarios de la IS a realizarse en Caracas. El PLN propuso a través de Daniel Oduber, que sólo fueran invitados los partidos miembros plenos, para dejar fuera de juego al FSLN que aún no tenía ese status dentro de la organización. Sin embargo, no tuvo eco en la conducción de la IS que procedió a hacer las invitaciones sin tomar la sugerencia costarricense.

Cuando los dirigentes venezolanos de $\mathrm{AD}$ fueron notificados que los sandinistas también estaban invitados a la reunión en Caracas, entraron en un debate interno sobre la conveniencia de recibirlos o no. En una charla telefónica de Carlsson con el dirigente de AD Enrique Tejera País, éste reafirmaba que apoyaban la idea de Oduber de no permitir el ingreso de observadores ni invitados.

Carlsson le explicó que no era tan fácil volver atrás con las invitaciones, a lo que Tejera País contestó que nadie criticaría esa decisión en Venezuela, ya que la prensa estaba con AD por este tema. ${ }^{68}$

El pedido de no invitar a los sandinistas estaba sostenido tanto en los desacuerdos políticos como en el desgaste que eso podría generarle a $\mathrm{AD}$ dentro del país.

[Deseamos] manifestar, muy a nuestro pesar, el desacuerdo con la presencia de los jefes sandinistas [...] No sólo por los problemas que internamente nos causarán, sino al igual, porque éticamente parece que

\footnotetext{
${ }^{66}$ Rita Freedman, delegada de DSOC escribió un artículo muy crítico a Granada, Nicaragua y la actitud condescendiente de la IS. Decía que en la isla se cierran medios y se encarcelaba opositores. Además afirmaba que 3 días después de la reunión recibieron ayuda cubana en armas y hombres. Extractado de The Wall Street Journal, 24/08/1981, IISG.

${ }^{67}$ Points for letter to WB on meeting in Grenada, by Bernt Carlsson, 3/08/1981, IISG. 68 Notes on phone talk with Enrique Tejera Paris 14/02/1982, IISG.
} 
Fernando Pedrosa, Partidos políticos y acciones trasnacionales: El Comité para América Latina y el Caribe de la Internacional Socialista (1976-1983) / Political parties and transnational actions: The Socialist International Committee for Latin America and the Caribbean (1976-1983), Revista Izquierdas.cl, número 22, enero 2015, ISSN 0718-5049, Santiago de Chile, pp. 48-77

no es posible continuar sirviéndole, de cobertura para su proceso marxista-leninista". ${ }^{69}$

Además, $\mathrm{AD}$ deseaba plantear sus dudas sobre el rumbo de la revolución de modo que la presencia sandinista no suponía el mejor escenario para eso, ya que los obligaría a moverse entre opciones radicales como apoyarlos o retirarles el apoyo.

Además creemos que la reunión debe tener la amplitud necesaria para analizar objetiva $\mathrm{y}$ francamente la situación de Centroamérica [...] Pensamos que ahora sólo procede el análisis que podríamos realizar serenamente en la reunión de Caracas sin la presencia de sandinista y sin retirar ni ratificar nuestra solidaridad". 70

La suspensión de la reunión fue uno de los peores momentos de la IS desde 1976 y llamativamente difundido por la prensa de toda la región (Pedrosa, 2012). La fractura en el ala latinoamericana de la organización socialdemócrata quedaba expuesta a la luz del día y nada hacía suponer que las cosas iban a mejorar.

\section{El CALCIS en guerra}

Cuando aún no se habían calmado las aguas entre los dirigentes de la IS, la guerra de las Malvinas dinamitó definitivamente la posibilidad de una acción trasnacional conjunta y coordinada desde la IS. ${ }^{71}$ En el clima de incertidumbre y confusión que la guerra había desatado, la IS parecía no tomar posición más que alguna vaga apelación al cese del conflicto y el respeto a la ONU.

Sin consultarlo con las autoridades de la IS, un comunicado del CALCIS puso el tema Malvinas en el centro de la agenda socialdemócrata. ${ }^{72}$ La gran difusión que tuvo lo convirtió en una bomba de tiempo, potenciada por los conflictos que anteriormente se venían desarrollando ${ }^{73}$.

Esto, además de enrarecer el clima interno de la IS, complicaba seriamente la situación del Partido Laborista Británico (PLB) que se encontraba en medio de una importante disputa electoral donde el clima nacionalista crecía con el avance de la guerra, al punto de convertirse en uno de los principales issues de la campaña.

69 Carta de Carlos A. Pérez y Gonzalo Barrios a Willy Brandt, Caracas, 3/02/1982, IISG.

70 Carta de Carlos Andrés Pérez y Gonzalo Barrios a Willy Brandt, Caracas, 3/02/1982, IISG.

${ }^{71}$ En Pedrosa (2014) se presenta una detallada descripción del impacto de la guerra en la IS.

72 “Sostuvimos varias consultas telefónicas con Carlos Andrés Pérez y los demás miembros del comité y arribamos a la posición plasmada en la declaración anexa. Este documento no fue suscripto por los compañeros angloparlantes Michael Manley (Jamaica) y O’Brian Trotman (Barbados) pues no llegamos a un acuerdo satisfactorio". Circular del CALC 3/82, IISG.

${ }^{73}$ Además, la declaración, fue profusamente distribuida entre los miembros de la organización por el mismo Secretario General, Bernt Carlsson, quien mantenía un viejo encono con el laborismo. 
Fernando Pedrosa, Partidos políticos y acciones trasnacionales: El Comité para América Latina y el Caribe de la Internacional Socialista (1976-1983) / Political parties and transnational actions: The Socialist International Committee for Latin America and the Caribbean (1976-1983), Revista Izquierdas.cl, número 22, enero 2015, ISSN 0718-5049, Santiago de Chile, pp. 48-77

El CALCIS afirmaba sin vueltas que "Las Malvinas son argentinas" y a la vez se cuestionaba a sus pares europeos por las sanciones económicas asimilando el interés argentino al de toda Latinoamérica. Al mismo tiempo no se mencionaban las características no democráticas del gobierno argentino. ${ }^{74}$

La percepción de que EE.UU. y Europa habían "traicionado" a América Latina y que ésta se encontraba sola frente los países desarrollados, caló profundamente en los gobiernos y los partidos del continente, incluso en los que no estaban relacionados con la socialdemocracia. $^{75}$

A la coyuntura crítica que abordaba el proyecto Norte/Sur, se sumaban las insalvables diferencias por Centroamérica, la crisis económica que comenzaba ese mismo año (la llamada "crisis de la deuda") y el aislamiento político que los países latinoamericanos sufrían frente a la polarización del mapa geopolítico. La guerra de Malvinas llamaba a la realidad a los políticos de América Latina sobre su verdadera influencia en el mundo y eso pronto impactó en la IS.

\section{La vuelta del CALCIS}

Apenas terminada la guerra, y a instancias de algunos partidos latinoamericanos y europeos, se decidió convocar a una nueva reunión del CALCIS en República Dominicana para intentar recomponer lo que ya parecía no tener arreglo. La idea era generar algún tipo de refuerzo a la idea colectiva que había sostenido a la IS desde 1976 y que parecía definitivamente dañada después de la guerra.

Se intentó repetir aquel encuentro inicial de 1980, incorporando la reunión del CALCIS en un evento mayor, en este caso, el apoyo a la democracia en el país caribeño en ocasión de la asunción de Salvador Jorge Blanco como nuevo presidente. El encuentro nuevamente se caracterizó por los problemas organizativos que el CALCIS venía arrastrando y que más que ineficiencia, mostraba los conflictos estructurales que arrastraba la estrategia de acumulación de la organización (Pedrosa, 2012).

La reunión del CALCIS fue un nuevo fracaso y la discusión acerca de la forma en que debía funcionar (un tema clave en opinión de Carlsson), nuevamente se pospuso. Esto se

74 "El CALCIS [...] manifiesta su plena solidaridad con el fraterno pueblo argentino [...] y su rechazo a la guerra como medio de poner fin a las controversias entre los estados [...] Las Malvinas son argentinas. [...] solicitamos de los partidos europeos afiliados [...] su gestión frente a los gobiernos europeos para que unan sus esfuerzos en la mediación y adopten una actitud considerada y comprensiva con los pueblos de AL que no podemos entender ni aceptar las precipitadas y drásticas acciones que ha adoptado la CEE" Circular del CALC 3/82. Santo Domingo, Abril 28 de 1982 Firmado por José Peña Gómez. IISG.

75 "El presidente ecuatoriano, Osvaldo Hurtado, agradeció a (Leopoldo) Calvo Sotelo el "apoyo que ya ha comenzado a prestarse en la reciente crisis de las Malvinas con el respaldo prestado por la diplomacia española en esta gran causa latinoamericana [...] Extractado de Diario El País. 07/08/1982. 
Fernando Pedrosa, Partidos políticos y acciones trasnacionales: El Comité para América Latina y el Caribe de la Internacional Socialista (1976-1983) / Political parties and transnational actions: The Socialist International Committee for Latin America and the Caribbean (1976-1983), Revista Izquierdas.cl, número 22, enero 2015, ISSN 0718-5049, Santiago de Chile, pp. 48-77

vio en la presencia de numerosas organizaciones no pertenecientes a la IS y la ausencia significativa de otras que pertenecían a ella.

A pesar de encontrarse en el país con motivo de la asunción de Blanco, no concurrió nadie de los partidos alemán, español ni de la Fundación Ebert, lo cual era llamativo ya que habían financiado el evento. Ni siquiera se organizó adecuadamente la redacción de un comunicado y este terminó de ser redactado cuando los delegados ya se marchaban de la Isla.

Carlsson observó con incredulidad que en el mismo recinto del encuentro, se encontraba George Lister, un diplomático del Departamento de Estado norteamericano invitado por Peña Gómez. ${ }^{76}$ Carlsson públicamente tuvo que pedirle que se retire de la reunión. ${ }^{77}$ Una vez comenzado el encuentro, sólo dos partidos miembros de la IS se encontraban presentes y el resto eran todos invitados y observadores.

En un aparte, la delegada francesa, Nicole Bourdillat, planteó a Carlsson que la organización era un caos y que el CALCIS había perdido identidad pareciéndose más a un encuentro de la COPPPAL. Carlsson se limitó a recordarle que cuando él propuso un modelo diferente de organización, el socialismo francés y Brandt se opusieron a ello. Carlsson recibió también la queja de O’Brien Trotman (Barbados), quien no firmó la declaración de apoyo a la democracia dominicana porque no había sido traducida al inglés. $^{78}$

El dato más importante fue el anuncio que Peña Gómez presentaría su renuncia a la presidencia del CALCIS por haber sido electo alcalde de Santo Domingo. Sin embargo, Carlsson atribuyó esta decisión a motivos menos trascendentes como la posible falta de financiamiento producto de la crisis mexicana. También por el affaire Malvinas y la mala imagen que el CALCIS se había formado ante los partidos europeos.

A esta altura los escritos de Carlsson reflejaban un profundo hartazgo. Así cuando Peña Gómez afirmaba que su asunción como alcalde se producía siguiendo el camino de otros grandes líderes, Carlsson escribía burlonamente que Peña Gómez debía recordar que el primer alcalde fue el hermano de Cristóbal Colon. Pero lo peor estaría por llegar. Cuando Peña Gómez estaba por cerrar el encuentro, Brizola solicitó decir algunas "pocas palabras" que se extienden casi una hora más.

La situación de la IS en América Latina entraba en su peor momento. La convocatoria a una reunión en Bolivia nunca llegó a concretarse por conflictos entre Hernán Siles Suazo y Jaime Paz Zamora. La relación de AD, PLN y el socialismo español con Nicaragua y El

\footnotetext{
${ }^{76}$ Confidential. Some notes on the meeting of the CALCIS, Santo Domingo, 14/15/08/1982, IISG.

77 “Peña Gómez se defendió diciendo que Lister era un buen hombre. Yo le pedí a Lister que se retire de la reunión. Mala atmosfera". Mi traducción. Draft Notes of meeting of CALCIS, IISG.

${ }^{78}$ Draft Notes of meeting of CALCIS, IISG.
} 
Fernando Pedrosa, Partidos políticos y acciones trasnacionales: El Comité para América Latina y el Caribe de la Internacional Socialista (1976-1983) / Political parties and transnational actions: The Socialist International Committee for Latin America and the Caribbean (1976-1983), Revista Izquierdas.cl, número 22, enero 2015, ISSN 0718-5049, Santiago de Chile, pp. 48-77

Salvador se deterioraban crecientemente, a pesar del triunfo del PLN en las presidenciales. La IS de todos modos siguió apoyando al FSLN.

La caótica situación de la rama latinoamericana llevó a rediscutir el modelo de expansión en el continente y Brandt, finalmente, comenzó a reconocer la necesidad de un cambio en el CALCIS. $^{79}$

Sin embargo, esto fue quedando de lado porque en 1983 la política norteamericana también se radicalizó y luego del informe Kissinger cada vez quedó menos lugar para acciones trasnacionales distintas a las apoyadas por Washington. La invasión de EE.UU. a Granada ese mismo año fue un mensaje contundente del cambio de época.

También en 1983 se realizaría el congreso de la IS que implicó grandes problemas y cambios en la organización. Entre ellos, el reemplazo de Carlsson y una mayor centralización del poder de la organización en manos de Brandt y su grupo en detrimento de la acción colectiva que había caracterizado a la IS desde 1976.

\section{Conclusiones}

La última reunión del CALCIS realizada en 1982 mostró un ambiente de discordia y descontento contrapuesto al optimismo fundacional de 1980 en República Dominicana. La pregunta es ¿por qué la IS no varió su política hacia los sandinistas y el FMLN a pesar del descontento que producía en sus socios latinoamericanos?

Una posible respuesta a esa pregunta es que no podía hacer otra cosa. Brandt y su grupo apostaban a convertir a la IS en un actor geopolítico de importancia y si rompían relaciones con los grupos revolucionarios de Centroamérica perdían al mismo tiempo todo su valor como interlocutores, transmisores y receptores de información renunciando, por esto, a influir políticamente en la zona.

Es cierto que la IS intentó presionar de diversas formas al sandinismo y que, de algún modo, las elecciones de 1984 son también mérito de la IS. Pero aun sabiendo que el gobierno nicaragüense se radicalizaba, la IS no le quitó su apoyo público en ningún momento. Lo mismo puede decirse del FDR y el MNR en El Salvador, el PSD en Guatemala y en menor medida con los granadinos.

Al mismo tiempo, otros partidos tradicionales de la IS tenían una visión muy izquierdista en lo referido a la política internacional. Por ello no estaban dispuestos a quitar su apoyo a los movimientos de liberación. Este fue el caso de los nórdicos, donde, además de la ideología, había electorados muy activos e interesados en la materia.

\footnotetext{
${ }^{79}$ Some privates notes on the meeting in Bonn in the political club of the FES, with Willy Brandt, Klaus Lindenberg and Thomas Mirow, 26/11/1982, IISG.
} 
El mismo socialismo francés, en el gobierno desde 1981 en una alianza con el PC, alentó a los sandinistas y reconoció públicamente al FMLN. Y también el grupo que quedó al mando del laborismo inglés luego de la división. ${ }^{80}$ De algún modo Leonel Jospin lo había advertido en su carta a Brandt, en los conflictos latinoamericanos no podía ocurrir que estos sean los moderados y los europeos los radicales.

La guerra de Malvinas fue una muestra de las diferencias profundas que guiaban el accionar de los partidos latinoamericanos y europeos. En este sentido, mostró que mientras los primeros leyeron el conflicto en la clave colonización-descolonización, los europeos lo hicieron en función de la coyuntura democracia-dictadura.

Desde 1980 las presiones del entorno comenzaron a jugar un importante papel dentro del devenir organizativo de la IS. La asunción de Reagan y la crisis económica que abrió la década de 1980, no fueron elementos positivos para la organización que, pasaba así de un entorno positivo a otro hostil, para sus deseos de expansión.

Esta situación no era ignorada por las máximas autoridades de la IS, sin embargo, poco era lo que podían hacer al respecto. Los mismos miembros de la IS comenzaban a recibir distintas presiones para priorizar sus intereses primarios (como organización partidaria nacional), antes que la construcción colectiva que se había mantenido a partir de 1976.

A partir de 1983 la organización trasnacional socialdemócrata entró en un proceso de lenta decadencia que se aceleró con el asesinato de Olof Palme en 1986 y la caída en desgracia de varios de sus referentes latinoamericanos.

Recibido: 6 septiembre 2014

Aceptado: 19 noviembre 2014

\section{Bibliografía}

Angell, Alan "La izquierda en América Latina desde 1920", en Bethell, Leslie (comp.), Historia de América Latina, Tomo 12. Barcelona: Crítica, 1991.

Brandt, W., Kreisky, B., y Palme. O. La alternativa socialdemócrata. Editorial Blume: Barcelona, 1975.

Camacho Padilla, Fernando. "Las relaciones entre Chile y Suecia durante el primer gobierno de Olof Palme, 1969-1976”. Iberoamericana. (7) 25 (2007), pp. 65-85.

${ }^{80}$. Carta de Ron Hayward (General Secretary, Labour Party) a Bernt Carlsson, Londres, 20/07/1981, IISG. 
Fernando Pedrosa, Partidos políticos y acciones trasnacionales: El Comité para América Latina y el Caribe de la Internacional Socialista (1976-1983) / Political parties and transnational actions: The Socialist International Committee for Latin America and the Caribbean (1976-1983), Revista Izquierdas.cl, número 22, enero 2015, ISSN 0718-5049, Santiago de Chile, pp. 48-77

Covarruvias, Ana, "El papel de la política exterior de México en el proceso de paz en El Salvador" Revista Mexicana de Política Exterior. Número especial (2013), pp 39-62.

Devin, G. L'Internationale socialiste: histoire et sociologie du socialisme international (1945-1990) Paris: Presses de la Fondation Nationale des Sciences Politiques, 1993.

Freeman, Alan. "El laborismo británico: el dilema de las alianzas". Nueva Sociedad 72 (1984), pp. 68-77.

Gamus, Raquel: "El contenido de la política exterior del gobierno de Carlos Andrés Pérez (1974-1979). Expectativas para el nuevo quinquenio”. Anuario del Instituto de Estudios Hispanoamericanos. Caracas: Ediciones UCV (1988-1989), pp.125-141.

Grabendorff, Wolf. "International support for democracy in contemporary Latin America: The rol of the party internationals". In Whitehead, L. (ed). The International Dimensions of Democratization. Europe and the Americas. Oxford: Oxford University Press, 2002.

Granovetter, Mark S. "The strength of weak ties". American Journal of Sociology; vol 78, $n^{\circ}$ 6, (1973). pp. $1360-1380$.

Halliday, Fred. The Making of the Second Cold War, Londres: Verso, 1986.

Hartlyn, Jonathan. The struggle for democratic politics in the The Dominican Republic. Chapell Hill: The University of North Carolina Press, 1998.

Heine Jorge. Revolución e intervención en el Caribe: las lecciones de Granada. GEL: Buenos Aires, 1990.

Huntington, Samuel: La tercera ola. La democratización a finales del siglo XX. España: Paidós Estado y Sociedad, 1994

Keck, Margaret y Kathryn Sikkink. Activistas sin fronteras. México: Siglo XXI, 2000.

Keohane Robert and Joseph Nye. eds. Transnational Relations and World Politics. USA: Harvard University Press, 1971.

Kissinger, Henry. Informe de la Comisión Presidencial Bipartita de los Estados Unidos sobre Centroamérica. Barcelona: Planeta, 1984.

Lvovich, Daniel; Ernesto Bohoslavsky; Marina Franco; Mariana Iglesias (Comp.): Problemas de historia reciente del Cono Sur. Bs. As: Prometeo Libros, 2011. 
Fernando Pedrosa, Partidos políticos y acciones trasnacionales: El Comité para América Latina y el Caribe de la Internacional Socialista (1976-1983) / Political parties and transnational actions: The Socialist International Committee for Latin America and the Caribbean (1976-1983), Revista Izquierdas.cl, número 22, enero 2015, ISSN 0718-5049, Santiago de Chile, pp. 48-77

Malefakis, Edward. "Spain and its Francoist Heritage" En HERTZ, JOHN. From dictatorship to democracy. Coping with the legacies of Authoritarianism and totalitarianism. Londres: Grenwood Press, 1982.

Martínez Peñate, Oscar. El Salvador del Conflicto Armado a la Negociación (1979-1989). San Salvador: Editorial Nuevo Enfoque, 1995.

Martínez Peñate, Oscar. "La diplomacia paralela en el conflicto armado salvadoreño" Cuadernos de Marte Año 3, nro. 4, (2013), pp. 187-206.

Markarian, Vania. La izquierda uruguaya en el exilio y las redes transnacionales de derechos humanos (1972-1976). Cuadernos del CLAEH, No. 89, Montevideo: Centro Latinoamericano de Economía Humana, 2004.

Meschkat, Klaus: "El Socialismo Latinoamericano y su rescate del pasado" . En Revista iZQUIERDAS, Año 3, Número 7, (2010), pp. 1-14.

Mira Delli-Zotti, Guillermo. "Transiciones a la democracia y democratización en América Latina: un análisis desde la historia del presente". En Actas del XIV Encuentro de Latinoamericanistas Españoles, España, 2010.

Morlino, Leonardo. Cómo cambian los regímenes políticos. Madrid: CEC, 1985.

Mujal León, Eusebio. European Socialism and the conflict in Central America. Washington: Center for Strategic and International Studies, 1989.

Muñoz Sánchez, Antonio: “La Fundación Ebert y el socialismo español de la dictadura a la democracia" Cuadernos de Historia Contemporánea $\mathrm{N}^{\circ} 29$, (2007), pp. 257-278.

O' Donnell, Guillermo, Philippe Schmitter y Lawrence Whitehead (Comp.): Transiciones desde un gobierno autoritario. Perspectivas comparadas. Barcelona: Paidós, 1998.

Ortuño Anaya, Pilar. Los socialistas europeos y la transición española. Madrid: Marcial Pons Historia, 2005.

Pedrosa, Fernando. La otra izquierda. La socialdemocracia en América Latina. Buenos Aires: Capital Intelectual, 2012.

Pedrosa, Fernando "La Internacional Socialista y la Guerra de las Malvinas" Latin American Research Review . Vol. 49, No 2. (2014), pp. 47-67.

Powell, Charles. La dimensión exterior de la transición española. Revista CIDOB D’Afers Internacionals, (1993), No 26, pp: 37-64 
Fernando Pedrosa, Partidos políticos y acciones trasnacionales: El Comité para América Latina y el Caribe de la Internacional Socialista (1976-1983) / Political parties and transnational actions: The Socialist International Committee for Latin America and the Caribbean (1976-1983), Revista Izquierdas.cl, número 22, enero 2015, ISSN 0718-5049, Santiago de Chile, pp. 48-77

Pridham, Geoffrey (Edited) Encouraging Democracy. The international context of regime transition in Southern Europe. Gran Bretaña: Leicester University Press, 1991.

Schmitter, Philippe "Veinticinco años, quince hallazgos". En Postdata. (16) 1, (2011), pp. 25/30.

Schori, Pierre. Escila y Caribdis. Olof Palme, la Guerra Fría y el poscomunismo. Fondo de Cultura Económica: México, 1994.

Santos Villarreal, Gabriel Mario. La Conferencia de Partidos Políticos de América Latina (COPPPAL). Declaraciones, resoluciones y otros documentos 2000-2009. Centro de Documentación, Información y Análisis. Cámara de diputados. México.

Ulianova, Olga: "Relaciones internacionales y redefiniciones en el socialismo chileno, 1973-1979”. Revista iZQUIERDAS. Año 3, Número 4 (2009), pp. 1-30.

Whitehead, Lawrence. "Aspectos internacionales de la democratización” en O’Donnell, G. P. Schmitter y L. Whitehead. Transiciones desde un gobierno autoritario/3. Perspectivas comparadas. Capítulo 1. Ediciones Paidós. Buenos Aires, 1994.

Whitehead, Lawrence (ed): The International Dimensions of Democratization. Europe and the Americas. Oxford: Oxford University Press, 1992. 